RESEARCH ARTICLE



open acCess

Received: 24.11.2020

Accepted: 05.01.2021

Published: 15.01.2021

Citation: Gaware MR (2021) Studies of molar refraction and polarizability constant of 6-(4-chlorophenyl)-

1,2,3,4-tetrahydro-2,

4-dioxopyrimidine-5-carbonitrile in $60 \%$ DMSO in the temperature range 298 to $313 \mathrm{~K}$. Indian Journal of Science and Technology 14(2):

113-118. https://doi.org/ 10.17485/IJST/v14i2.2118

* Corresponding author.

Tel: +9193702935304

gawaremanoj@rediff.com

Funding: None

Competing Interests: None

Copyright: (c) 2021 Gaware. This is an open access article distributed under the terms of the Creative Commons Attribution License, which permits unrestricted use, distribution, and reproduction in any medium, provided the original author and source are credited.

Published By Indian Society for Education and Environment (iSee)

ISSN

Print: 0974-6846

Electronic: 0974-5645

\section{Studies of molar refraction and polarizability constant of 6-(4-chlorophenyl)-1,2,3,4-tetrahydro-2, 4-dioxopyrimidine-5-carbonitrile in 60\% DMSO in the temperature range 298 to $313 \mathrm{~K}$}

\section{Manoj R Gaware ${ }^{1 *}$}

1 Department of Chemistry, M. V. P. Samaj's K.P.G. Arts, Science and Commerce College, Igatpuri, Nashik, 422 403, Maharashtra, India. Tel.: +9193702935304

\section{Abstract}

Objectives: The main purpose of this study is to investigate the impact of 6-(4-chlorophenyl)-1, 2, 3, 4-tetrahydro-2, 4-dioxopyrimidine-5-carbonitrile in binary solution at different concentrations and valuable information on electronic polarizability and molecular interactions in the solution. Methods : 6-(4-chlorophenyl)-1, 2, 3, 4-tetrahydro-2, 4-dioxopyrimidine-5-carbonitrile was synthesized and purified by recrystallization technique in laboratory ${ }^{(1)}$. DMSO used is of analytical reagent grade (AR) of minimum assay of $99.9 \%$. Stock solutions of $0.02\left(\mathrm{~mol} \mathrm{~L}^{-1}\right)$ of compound were prepared by dissolving calculated amounts in $60 \%$ dimethyl sulphoxide solution. Solutions in various concentration ranges from 0.002 to $0.010\left(\mathrm{~mol} \mathrm{~L}^{-1}\right)$. The pycknometer was calibrated by measuring the densities of triple distilled water. The densities of distilled organic liquids like acetone, toluene and carbon tetrachloride were evaluated with respect to density of water. Refractive index were measured by Abbe's Refractometer (AR-56, COSLAB) having range 1.3000 to 1.7100. The desired temperature was maintained by circulating water through refractometer. Findings: In the present work we found that density, refractive index, molar refraction and polarizability constant increases the increase in concentration due to decrease in angle of refraction or increase in angle of incidence. The decrease in density with increase in temperature is due to increase in molar volume of solvent. However, the decrease in refractive index is due to the fact that the solute-solute and solute-solvent interactions weaken with increase in temperature. This can be correlated that change in these properties changes the intermolecular attraction between solute and solvent. With increase in temperature the interaction between solute and solvent weakens and hence molar refraction and polarizability decreases. Novelty: The work incorporated with the study of molar refraction and molar polarizability of 6-(4-chlorophenyl)-1, 2, 3, 4-tetrahydro-2, 4-dioxopyrimidine-5-carbonitrile 
has been not studied until now. So we wish to present the systematic measurement of refractive index of 6-(4-chlorophenyl)-1, 2, 3, 4-tetrahydro-2, 4-dioxopyrimidine-5-carbonitrile in 60\% DMSO in the temperature range 298 to $313 \mathrm{~K}$ at different concentration. From refractive index we have calculated molar refraction and molar polarizability which has provided important information regarding interactions between solute and solvent.

Keywords: 6-(4-chlorophenyl)-1; 2; 3; 4-tetrahydro-2;

4-dioxopyrimidine-5-carbonitrile; refractive index; molar refraction; molar polarizability

\section{Introduction}

Pyrimidines are heterocyclic compounds having various biological significance and biological activities ${ }^{(2-4)}$. The interaction of organic compounds with polar aprotic solvent is important to study physiological action, pharmacodynamics, pharmakinetic in living organism. The intermolecular interaction between solute and solvent can be studies by properties like density, viscosity, conductivity, refractive index ${ }^{(5-7)}$. Refractive index is an important additive property of molecular structure of liquid and can be measured easily with high degree of accuracy. Refractive index is property which passing of light beam through rarer to denser medium which causes bending of light toward normal in such away that ratio of Sin angle of incidence to Sin angle of refraction is constant (Snell's Law). The extent of refraction depends on relative concentration of atom or molecules and the structure of molecule. It also gives an idea about geometry, structure of molecule. It is additive property and depends on om structural arrangement of atom in molecule. This structural arrangement in responsible for interactions in solvent medium. To understand different interactions, refractive index, molar refraction and polarizability constant of various mixtures are studied by various researchers ${ }^{(8-14)}$.

\section{Result and Discussion}

The present investigation considers the density and refractive measurement of 6-(4chlorophenyl)-1, 2, 3, 4-tetrahydro-2, 4-dioxopyrimidine-5-carbonitrile in $60 \%$ binary mixtures of DMSO-water in different concentration at temperature 298 to $313 \mathrm{~K}$. Use of molar refraction $\left(\mathrm{R}_{m}\right)$ and Polarizability constant $(\alpha)$ plays an important role in studying drug interaction. They are related with intermolecular forces also. Hence, they are applicable to study drug design, QSRR and QSAR studies ${ }^{(15)}$ and plays important role in modeling many molecular properties and biological activities. The results obtained are reported in the tables and respective graphical representations are shown in graphs. The molar refraction and polarizability constant for solvent and solution are determined by using Lorentz-Lorentz equation as

$$
\mathrm{R}_{\mathrm{m}}=\frac{\mathrm{n}^{2}-1}{\mathrm{n}^{2}+2} \times \frac{M}{d}=\frac{4}{3} \pi \mathrm{N} \alpha
$$

Where, $\mathrm{n}$ is the refractive index of solution, $\mathrm{M}$ is the molecular weight of solution, $\mathrm{N}$ is the Avogadro's constant and $\alpha$ is the polarizability constant.

The calculated values of molar refraction and polarizability constant are presented in Tables 1, 2, 3 and 4. Variation of refractive index with concentration is shown in Figure 1 by plotting graph of refractive index $(n)$ verses concentration $(C)$. Concentration dependence of refractive index is studied by equation

$$
\mathrm{n}=\mathrm{K} \times \mathrm{C}+\mathrm{n}^{0}
$$

Where, $\mathrm{n}$ is the refractive index of solution $\mathrm{K}$ is the slope and $\mathrm{n}^{0}$ is the intercept. 
It is seen that both $\mathrm{R}_{m}$ and $\alpha$ increases with increase in concentration and decreases with temperature. This shows that as temperature increases there is decrease in the polarizability which results in decrease in interaction between solute and solvent. The values of $\mathrm{Rm}$ and $\alpha$ are higher at low concentration and low temperature. The variation of molar refraction and polarizability constant for 6-(4-chlorophenyl)-1, 2, 3, 4-tetrahydro-2, 4-dioxopyrimidine-5-carbonitrile with concentration at different temperature is shown in Figures 2 and 3.

It is also clearly seen that the refractive index of various solutions shows a linear relationship with concentrations. Temperature dependent quantity, specific refraction characterizes electronic polarizability of a substance. The increase value of molar refraction $\left(\mathrm{R}_{m}\right)$ indicates strong solute-solvent interactions. On the basis of the results of Fajan's and co-workers ${ }^{(16)}$ it can be concluded that

1. The refractivity of compound is lowered by neighboring solvent molecules. It is lowered more in the presence of polar solvent molecules.

2. The combination of compound in aqueous DMSO is then accompanied by a net increase in the refractivity.

3. The close perusal of present investigation shows that there is increase in polarizability as well as molar refraction with increase in concentration. This may be due to dispersion force. It is the molecular force which arises from temporary dipole moment.

Table 1. Density, refractive index, molar refraction and polarizability constant for 6-(4-chlorophenyl)-1, 2, 3, 4-tetrahydro-2, 4-dioxopyrimidine-5-carbonitrile for different concentration at $298 \mathrm{~K}$

\begin{tabular}{|c|c|c|c|c|c|c|}
\hline Conc $\mathrm{molL}^{-1}$ & $\begin{array}{l}\text { Density (d) g } \\
\mathrm{cm}^{-3}\end{array}$ & $\begin{array}{l}\text { Refractive Index } \\
\text { (n) }\end{array}$ & $\begin{array}{l}\text { Molar Refraction }\left(\mathrm{R}_{m}\right) \\
\mathrm{cm}^{3} \mathrm{~mol}^{-1}\end{array}$ & $\begin{array}{l}\text { Polarizability constant } \\
(\alpha) \times 10^{-23}\end{array}$ & $\mathrm{n}_{0}$ & $\mathrm{~K}(\mathrm{~L}$ mol-1) \\
\hline 0.002 & 1.08657 & 1.4281 & 58.6145 & 2.32330 & \multirow{5}{*}{1.4280} & \multirow{5}{*}{0.0750} \\
\hline 0.004 & 1.08697 & 1.4283 & 58.6168 & 2.32338 & & \\
\hline 0.006 & 1.08734 & 1.4285 & 58.6208 & 2.32354 & & \\
\hline 0.008 & 1.0874 & 1.4286 & 58.6295 & 2.32388 & & \\
\hline 0.010 & 1.08755 & 1.4287 & 58.6334 & 2.32404 & & \\
\hline
\end{tabular}

Table 2. Density, refractive index, molar refraction and polarizability constant for 6-(4-chlorophenyl)-1, 2, 3, 4-tetrahydro-2, 4-dioxopyrimidine-5-carbonitrile for different concentration at $303 \mathrm{~K}$

\begin{tabular}{|c|c|c|c|c|c|c|c|}
\hline Conc molL $^{-1}$ & $\begin{array}{l}\text { Density (d) } \mathrm{g} \\
\mathrm{cm}^{-3}\end{array}$ & $\begin{array}{l}\text { Refractive } \\
\text { Index (n) }\end{array}$ & $\begin{array}{l}\text { Molar Refraction } \quad\left(\mathrm{R}_{m}\right) \\
\mathrm{cm}^{3} \mathrm{~mol}^{-1}\end{array}$ & $\begin{array}{l}\text { Polarizability } \\
(\alpha) \times 10^{-23}\end{array}$ & constant & $\mathrm{n}_{0}$ & $\begin{array}{l}\text { K (L mol- } \\
1)\end{array}$ \\
\hline 0.002 & 1.08473 & 1.427 & 58.5821 & 2.32200 & & \multirow{5}{*}{1.4269} & \multirow{5}{*}{0.0656} \\
\hline 0.004 & 1.0848 & 1.4271 & 58.5903 & 2.32233 & & & \\
\hline 0.006 & 1.08512 & 1.4273 & 58.5970 & 2.32260 & & & \\
\hline 0.008 & 1.08525 & 1.4274 & 58.6019 & 2.32279 & & & \\
\hline 0.010 & 1.08532 & 1.4275 & 58.6101 & 2.32312 & & & \\
\hline
\end{tabular}

Table 3. Density, refractive index, molar refraction and polarizability constant for 6-(4-chlorophenyl)-1, 2, 3, 4-tetrahydro-2, 4-dioxopyrimidine-5-carbonitrile for different concentration at $308 \mathrm{~K}$

\begin{tabular}{|c|c|c|c|c|c|c|}
\hline $\begin{array}{l}\text { Conc } \\
\text { molL }^{-1}\end{array}$ & $\begin{array}{l}\text { Density (d) g } \\
\mathrm{cm}^{-3}\end{array}$ & $\begin{array}{l}\text { Refractive Index } \\
\text { (n) }\end{array}$ & $\begin{array}{l}\text { Molar Refraction }\left(\mathrm{R}_{m}\right) \\
\mathrm{cm}^{3} \mathrm{~mol}^{-1}\end{array}$ & $\begin{array}{l}\text { Polarizability constant } \\
(\alpha) \times 10^{-23}\end{array}$ & $\mathrm{n}_{0}$ & $\begin{array}{l}\mathrm{K}(\mathrm{L} \text { mol- } \\
1)\end{array}$ \\
\hline 0.002 & 1.08356 & 1.4262 & 58.5493 & 2.32071 & & \\
\hline 0.004 & 1.08376 & 1.4263 & 58.5505 & 2.32075 & & \\
\hline 0.006 & 1.08383 & 1.4265 & 58.5707 & 2.32155 & 1.4261 & 0.0653 \\
\hline 0.008 & 1.08395 & 1.4266 & 58.5762 & 2.32177 & & \\
\hline 0.010 & 1.08412 & 1.4267 & 58.5790 & 2.32188 & & \\
\hline
\end{tabular}


Table 4. Density, refractive index, molar refraction and polarizability constant for 6-(4-chlorophenyl)-1, 2, 3, 4-tetrahydro-2, 4-dioxopyrimidine-5-carbonitrile for different concentration at $313 \mathrm{~K}$

\begin{tabular}{|c|c|c|c|c|c|c|}
\hline $\begin{array}{l}\text { Conc } \\
\text { molL }^{-1}\end{array}$ & $\begin{array}{l}\text { Density (d) } \mathrm{g} \\
\mathrm{cm}^{-3}\end{array}$ & $\begin{array}{l}\text { Refractive } \\
\text { Index (n) }\end{array}$ & $\begin{array}{l}\text { Molar Refraction }\left(\mathrm{R}_{m}\right) \\
\mathrm{cm}^{3} \mathrm{~mol}^{-1}\end{array}$ & $\begin{array}{l}\text { Polarizability constant } \\
(\alpha) \times 10^{-23}\end{array}$ & $\mathrm{n}_{0}$ & $\mathrm{~K}(\mathrm{~L} \mathrm{~mol}-1)$ \\
\hline 0.002 & 1.08156 & 1.4252 & 58.5372 & 2.32023 & \multirow{5}{*}{1.4251} & \multirow{5}{*}{0.0650} \\
\hline 0.004 & 1.08175 & 1.4253 & 58.5390 & 2.32030 & & \\
\hline 0.006 & 1.08193 & 1.4254 & 58.5412 & 2.32038 & & \\
\hline 0.008 & 1.08205 & 1.4256 & 58.5588 & 2.32108 & & \\
\hline 0.010 & 1.08223 & 1.4257 & 58.5611 & 2.32117 & & \\
\hline
\end{tabular}



Fig 1. Variation of refractive index (n) with concentration (C) of 6-(4-chlorophenyl)-1, 2, 3, 4-tetrahydro-2, 4-dioxopyrimidine-5-carbonitrile at different temperature

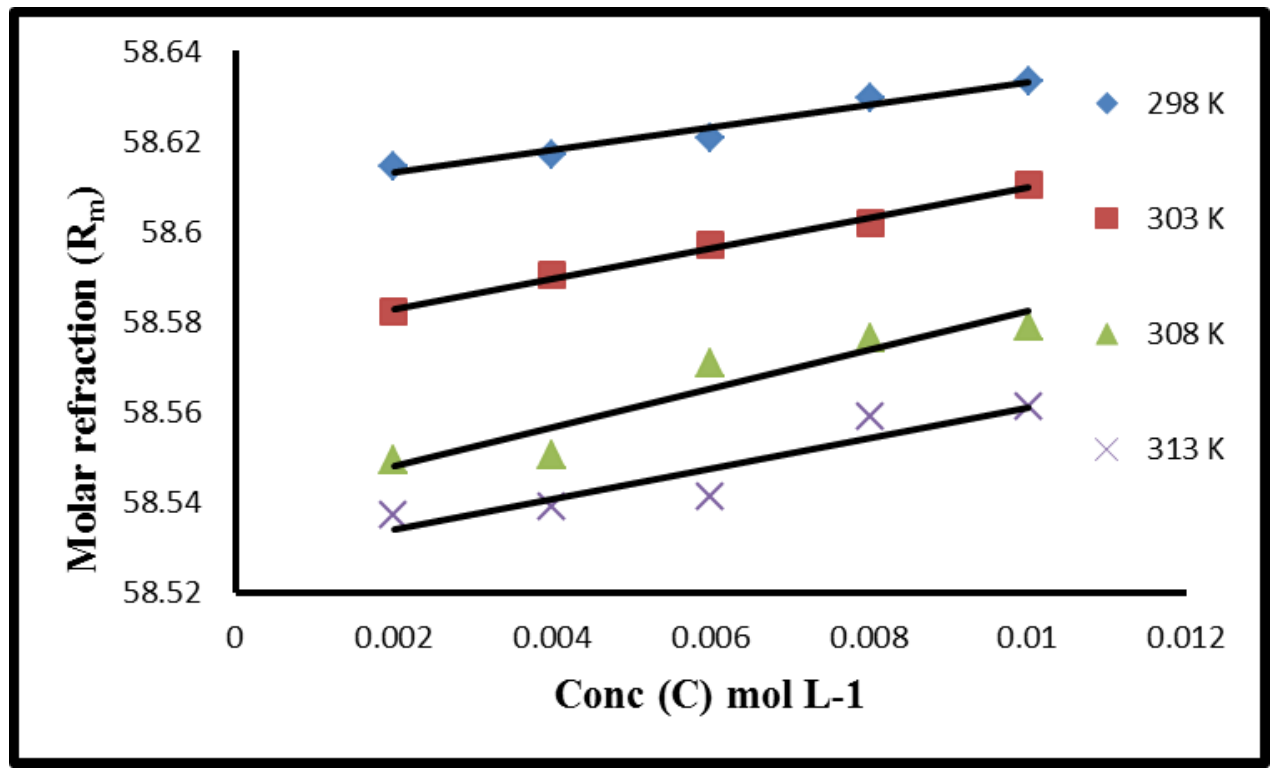

Fig 2. Variation of molar $\left(\mathrm{R}_{m}\right)$ for 6-(4-chlorophenyl)-1, 2, 3, 4-tetrahydro-2, 4-dioxopyrimidine-5-carbonitrile with concentration 




Fig 3. Variation of polarizability constant $(\alpha)$ for 6-(4-chlorophenyl)-1, 2, 3, 4-tetrahydro-2, 4-dioxopyrimidine-5-carbonitrile with concentration

\section{Conclusion}

It is concluded that density and refractive measurement are strongly dependent on concentration and temperature. The increase in densities with concentration may be due to strengthening of solute-solvent interactions. Density and refractive index shows linear relationship with concentration. The increase in polarizability as well as molar refraction with increase in concentration is due to dispersion force. Increase in concentration causes enhancement in polarizability to solution due to interaction between solute and solvent. But these interactions are found to decreases with increase in temperature. This decreasing magnitude indicates weak solute-solvent interactions.

\section{References}

1) Gaware MR, Aher JS, Lokhande DD, Tambade JS, Bhagare PJ, M A. A simple and efficient one pot synthesis of 2, 4 dioxopyrimidine carbonitrile and 4oxo-2- thioxopyrimidine carbonitrile derivatives using ammonium chloride under solvent free conditions. Ind J Chem-B. 2017;56(B):997-999. Available from: http://nopr.niscair.res.in/handle/123456789/42717.

2) Clark J, Shahhet MS, Korakas D, Varvounis G. Synthesis of thieno [2,3-d] pyrimidines from 4,6-dichloropyrimidine-5-carbaldehydes. Journal of Heterocyclic Chemistry. 1993;30:1065-1072. Available from: https://dx.doi.org/10.1002/jhet.5570300439.

3) Ogawva K, Yamawaki I, Matsusita YI, Nomura N, Kador PF, Kinoshita JH. Syntheses of substituted 2,4-dioxo-thienopyrimidin-1-acetic acids and their evaluation as aldose reductase inhibitors. European Journal of Medicinal Chemistry. 1993;28(10):769-781. Available from: https://dx.doi.org/10.1016/ 0223-5234(93)90112-r.

4) Tozkoparan B, Ertan M, Kelicen P, Demirdamar R. Synthesis and anti-inflammatory activities of some thiazolo [3,2-a] pyrimidine derivatives. Il Farmaco. 1999;54(9):588-593. Available from: https://dx.doi.org/10.1016/s0014-827x(99)00068-3.

5) Iqbal MJ, Chaudhary MA. Thermodynamic study of three pharmacologically significant drugs: Density, viscosity, and refractive index measurements at different temperatures. J Chem Thermodyn. 2009;41:221-226. Available from: https://doi.org/10.1016/j.jct.2008.09.016.

6) Banaik I, Roy MN. Relative viscosity and apparent molal volume of aqueous sodium sulfate at various temperatures. J Mol Liq. 2012;169:8-14. Available from: https://doi.org/10.1016/j.molliq.2012.03.006.

7) Deosarkar SD, Kalyankar TM. Structural properties of aqueous metoprolol succinate solutions. Density, viscosity, and refractive index at $311 \mathrm{~K}$. Russian Journal of Physical Chemistry A. 2013;87(6):1060-1062. Available from: https://dx.doi.org/10.1134/s0036024413060356.

8) Raikar SK, Aminabahvi TM, Harogoppad SB, Balundgi RH. Density, viscosity, refractive index and ultrasonic velocity of the binary mixtures formed by 1, 3, 5-trimethylbenzene with aliphatic hydrocarbons in the temperature range 298.15-308.15 K. Ind. J Tech. 1993;31:581-592.

9) Kapila VP, Gupta CM, Jauhar SP. Viscosity studies of some 1:1 electrolytes in acetic acid at 25C. Ind J Chem. 1991;30:711-713. Available from: http://nopr.niscair.res.in/handle/123456789/41966.

10) Verma RP, Kumar V, Sangal P. Characterisation of sodium soaps and their refractive index studies in methanol. Asian J Chem. 2000;12(3):659-662. 
11) Talegaonkar R, Burghate AS, Wadal SA. Study of molar refraction and polarizability constant of substituted thiazolyl schiff's bases from refractive index measurement in different media. Orient J Chem. 2011;27(3):1285-1288.

12) Deosarkar SD, Pawar MP, Sawale RT, Hardas AR, Kalyankar TM. Solvent effects on molar refraction and polarizability of 4-amino-5-chloro-N-(2(diethylamino) ethyl)-2 methoxybenzamidehydrochloride hydrate solutions at 3000C. J Chem Pharm Res. 2015;7(5):1107-1110.

13) Sawale R, Kalyankar T, George R, Deosarkar S. Molar Refraction and Polarizability of Antiemetic drug 4-amino-5-chloro-N-(2-(diethylamino)ethyl)-2 methoxybenzamide hydrochloride monohydrate in [Aqueous-Sodium or Lithium Chloride] Solutions at 30 and deg;C. Journal of Applied Pharmaceutical Science. 2016;6(3):120-124. Available from: https://dx.doi.org/10.7324/japs.2016.60321.

14) Yaseen SA, Alameen AS, Saif FA, Undre SB, Undre PB. Study of Volumetric and Optical Properties of Cerium Oxide Nano-Fluid. Journal of Physics: Conference Series. 2020;1644. Available from: https://dx.doi.org/10.1088/1742-6596/1644/1/012030.

15) Tiwari V, Pande R. Molecular Descriptors of N-Arylhydroxamic Acids: A Tool in Drug Design. Chemical Biology \& Drug Design. 2006;68(4):225-228. Available from: https://dx.doi.org/10.1111/j.1747-0285.2006.00433.x.

16) Fajans K, Luhdemann R. Refractometric investigations.XLIII. Non additivity of the equivalent refraction of strong electrolytes at high concentration. $Z$ Phys Chem. 1935. 